\title{
PROMOCIÓN JURÍDICA Y ORGANIZACIÓN MUNICIPAL DE COMPLUTUM EN EL ALTO IMPERIO*
}

\author{
M. ${ }^{a}$ PILAR GONZÁLEZ-CONDE PUENTE \\ Universidad de Alicante
}

\begin{abstract}
Sobre el emplazamiento del Cerro de San Juan del Viso se han encontrado huellas arqueológicas que permiten situar allí el antiguo emplazamiento de la ciudad de Complutum que, probablemente en época flavia, y al amparo del paso de personas y mercancías por el valle, se trasladó a su definitivo emplazamiento en el llano, junto al río Henares. Son abundantes los testimonios arqueológicos en la ciudad y sus alrededores, aunque escasos los que permitan seguir la evolución jurídica y administrativa del municipio. Aún así, es posible rastrear sus instituciones municipales, las formas religiosas, la estructura social y la escasa huella indígena en la ciudad, principalmente a lo largo de los dos primeros siglos del Imperio.

Archaeological remains on the site of the «Cerro de San Juan del Viso» allow to place here the ancient city of Complutum, which probably in the flavian period, and in relation to the traffic of people and goods along the valley, was moved to a new site on the plain, near the river Henares. Some of their archaeological remains make the study of aspects of the juridical and administrative evolution of the municipium possible: municipal institutions, religious forms, social structures and traces of the indigenous people, principally in the first two centuries of the Empire.
\end{abstract}

\section{LA PRIMITIVA OCUPACIÓN DEL CERRO DE SAN JUAN DEL VISO}

La localización de Complutum en el actual término de Alcalá de Henares le otorgó una situación privilegiada sobre el valle, en un importante centro de comunicaciones, en el paso de la vía que iba de Emerita a Caesaraugusta (1), lo que probablemen-

(*) Este trabajo constituye parte de nuestra Memoria de Licenciatura, dirigida por el Dr. D. Urbano Espinosa y leída el 22 de Junio de 1985 en la Universidad Complutense de Madrid. Agradecemos al Dr. Espinosa sus orientaciones para la realización del mismo, así como al Dr. Gèza Alföldy, de la Universidad de Heidelberg, sus amables sugerencias. te imprimió un determinado carácter a la ciudad romana.

El núcleo prerromano estaba situado en el cerro de San Juan del Viso, al suroeste del núcleo urbano actual (2), donde existiría un castro del tipo de los que han sido estudiados en Carpetania (VA-

(1) It. 436, 2. 438, 9. Rav. IV, $44(312,7.312,18.313$, 8-9).

(2) FERNÁNDEZ-GALIANO, 1976, croquis de los yacimientos romanos. El núcleo prerromano se ha querido identificar con Conbouto; al respecto, SANCHO ROCHER, 1981, 82; UNTERMANN, 1976, 219; VIVES, 1926, 85 ss., lám. XXXVII. 
LIENTE y BALMASEDA, 1983, passim). Corresponde este castro al «área del Tajo superior» de la clasificación hecha por Almagro Gorbea (1976-78, 146), quien describe el proceso de influencia ibérica que sufre la Meseta oriental. Esta misma idea ha sido comentada por E. Cuadrado (1976-78, 329), que habla de «clara asimilación» de lo ibérico en la Meseta meridional. En concreto, el autor cita la existencia del tesorillo de Alcalá de Henares (38 denarios de plata de la ceca de Bolscam) (GIL FARRES, 1966, 168) como signo del comercio que la Meseta llevaba a cabo con el área ibérica.

La existencia del núcleo indígena estaría en función de su situación junto a un curso de agua y, principalmente, de las posibilidades agrícolas del valle. Como tantos otros poblados de la Edad de Hierro en la Meseta, debieron buscar sus pobladores un lugar fácilmente defendible desde el que dominar las tierras de labranza, que estaban en todos los alrededores, al tiempo que la altura del cerro y su situación les permitía prepararse para cualquier ataque.

Es imposible delimitar el momento en que el castro entra dentro de la órbita romana. Las fuentes clásicas no han trasmitido noticias sobre su conquista, pero quizá este hecho se deba a que no la hubo en sentido propio, sino que en determinado momento, los habitantes de la Complutum indígena se convirtieron en aliados de los romanos, como otras ciudades de la Meseta, o simplemente adoptaron una posición neutral, ante la segura derrota y el miedo a perder la estabilidad social y política.

Para tener una noticia concreta de la ciudad hay que esperar a las guerras sertorianas, aunque tampoco esta vez se entabla batalla aquí, sino que sirve de lugar de paso a Sertorio cuando, tras la muerte de Hirtuleyo, el año 75 a. C., se retiró hacia Valencia (3).

Parece ser que, a la llegada de Roma, ya había allí un asentamiento importante sobre el que se empezaron a realizar algunas construcciones al modo romano. El material arqueológico del cerro se fecha, por lo que se refiere a los restos romanos, en la primera mitad del siglo I d. C., y corresponden a un hipocaustum, resto de unas termas que Fernández Galiano (4) supone de carácter público, así como un aljibe y algunos muros.

(3) Tito Livio, Per. 91. Frontino II, 3, 5. Floro II, 10, 7.
Paralelamente, las excavaciones llevadas a cabo entre el «Camino de la Dehesa» y el «Campo del Juncal», al suroeste de la ciudad actual, han proporcionado la mayor parte de los restos de lo que fue la Complutum romana, ya asentada en el valle del Henares. Como su propio excavador ha sugerido, el crecimiento urbano actual habría llegado a poner en peligro el futuro conocimiento del perímetro urbano de época romana, al quedar éste oculto por los barrios de nueva creación de Alcalá de Henares.

En esta zona del valle, excavada en numerosas campañas, los trabajos han dado material fechable desde mediados del siglo I d. C., pero que adquiere mayor intensidad en la segunda mitad de este siglo, lo que ha sugerido la idea de que hacia mediados del siglo I d. C., cuando la población seguía en el cerro, debía haber algunas construcciones en el valle, en función de la vía que por allí pasaba, y cuyo papel sería el de mansión para evitar el desvío de los viajeros hasta la ciudad alta (FERNÁNDEZGALIANO y MÉNDEZ MADARIAGA, 1984, 31). Hay que suponer que este pequeño núcleo formado abajo, tuviera más posibilidades de desarrollo que la propia ciudad ubicada en el cerro, porque podría cumplir una función importante, no sólo como punto de descanso de los viajeros, sino como lugar de comercio.

Como en tantos otros casos de mansiones, ésta debió ir adquiriendo poco a poco caracteres de auténtica ciudad, aunque no desde un punto de vista administrativo, ya que la sede de la ciudad peregrina seguiría arriba.

\section{LA ÉPOCA FLAVIA Y LA INTEGRACIÓN JURÍDICA DEL MUNICIPIO}

Durante el reinado de Vespasiano, la Península Ibérica sufre un proceso de transformación, especialmente en lo que al aspecto jurídico se refiere, que produjo un notable impulso de la vida municipal (5). Complutum no debió quedar al margen de

(4) FERNÁNDEZ-GALIANO y MÉNDEZ MADARIAGA, 1984, 22ss. Estando ya en pruebas este artículo han sido publicados los resultados de las excavaciones: FERNÁNDEZGALIANO, D. Complutum, EAE 137 y 138. Madrid 1984.

(5) McELDERRY, 1918, 53 ss., y 1919, 86 ss. GALSTERER, 1971. MONTENEGRO, 1975, 7 ss. GALSTERER, 1979 , 453 ss. 
este cambio, porque algún fenómeno parece producirse en ella durante la segunda mitad del siglo I. Para empezar, la vida de la ciudad debió ser más intensa en esa época, pero además, algunos edificios romanos construidos en el primitivo núcleo de San Juan del Viso fueron desmontados, y sus materiales aprovechados en la creación de otros nuevos en la otra margen del río Henares. Así ocurre, por ejemplo, con las termas (FERNÁNDEZGALIANO y MÉNDEZ MADARIAGA, 1984, 24).

¿Cuál es el motivo de esta actividad repentina en lo que sólo había comenzado siendo un punto de parada en la vía? ¿Es posible que estas transformaciones urbanas coincidan con un cambio de status jurídico? La epigrafía proporciona datos suficientes para estar seguros de que Complutum fue municipio latino. Para empezar, contamos con una inscripción honorífica (6) en la que figuran tres miembros de una misma familia, pertenecientes a tres generaciones: $C$. Nonius, Cn. Nonius Crescens y $C$. Nonius Sincerus, respectivamente abuelo, padre e hijo. En la inscripción, que está dedicada a Cn. Nonius Crescens, magister y flamen de Roma y Augusto, figura la abreviatura D.D. (Decreto Decurionum); se trata de una medida dictada por la Asamblea local, lo que indica la existencia de un ordo decurional que presupone una organización municipal.

Es esencial al municipio la existencia de un Senado local que, junto con los magistrados, gobernaba la ciudad. Esta Asamblea estaba integrada por los decuriones, que constituían la élite de estos núcleos urbanos, en alguno de los cuales sería escaso el número de familias que gozaran de la fortuna necesaria para ascender a este rango (GAGE, 1971, 163, sobre el mínimo de 100.000 sextercios exigido). Los ciudadanos que desempeñaban magistraturas, además de adquirir inmediatamente la ciudadanía (en el caso de que no la tuvieran ya) pasaban, después del año de ocupación del cargo, a formar parte del ordo decurionum. En el caso particular de Complutum no tenemos constancia del nombre de ningún magistrado municipal, ni de un decurión, pero el conocimiento que la inscripción de Cn. Nonius Crescens nos proporciona sobre un

(6) Cn(eo) Nonio / C(aii) Noni fil(io) / Quir(ina) (tribu) Crescent(i) / Mag(istro) Flamin(i) / Romae et Aug(usti) / D(ecreto) D(ecurionum) / C(aius) Nonius Sincerus / Patri. CIL II 3033. decreto de la Asamblea municipal es suficiente para reconocer su existencia. Sería un dato valiosísimo la datación, más o menos precisa, del epígrafe, lo que hasta el momento no ha sido posible.

El hecho mismo de la existencia del flaminado local, así como de un colegio de sevires (ETIEN$\mathrm{NE}, 1974 \mathrm{r}, 277$ y mapa 6), se interpreta como una prueba de peso que, unida a las otras, tiende a demostrar el status jurídico municipal en Complutum (7).

La pertenencia de una familia residente en Complutum a Ia tribu Quirina es otro dato aportado por la mencionada inscripción del flamen municipal. Una vez más se presenta el problema de la utilización de la adscripción a una tribu para intentar demostrar, no sólo el hecho mismo de la municipalización, que queda suficientemente probado, sino el momento en que se produce la misma.

El debate planteado sobre el problema de la tribu Quirina en relación con la obra de municipalización flavia, ha dado lugar a diversas opiniones, una más radicales que otras, que han sido recogidas y comentadas por U. Espinosa y A. Pérez Rodríguez (1982, 65 ss.) para el caso concreto de Tritium Magallum. En todo caso, conviene, en la medida en que ello sea posible, aportar otras pruebas que sirvan de argumento para demostrar el momento de la municipalización, en apoyo de la simple pertenencia a la citada tribu.

En Complutum la documentación epigráfica, aunque amplia y significativa, no ha arrojado apenas luz en lo que se refiere a magistraturas municipales, y la mención D(ecreto) y D(ecurionum) al no haber sido fechada, tampoco indica el momento en que se produce este decreto de la Asamblea municipal. El mismo problema de datación se presenta con respecto a la organización del culto imperial, que podría ser significativa del cambio de status jurídico. Así pues, tenemos que remitirnos a la documentación arqueológica y a las noticias de las fuentes clásicas para, relacionándolas con algunos datos epigráficos, buscar posibles soluciones a este interrogante.

Que Complutum fue ciudad peregrina durante parte del siglo I d. C., lo sabemos por la obra de Plinio (III, 24), que la recoge entre las ciudades estipendiarias del conventus Caesaraugustanus, lo

(7) Esta idea nos fue confirmada por el Dr. Gèza AlföIdy, a quien agradecemos su amabilidad. 
que proporciona un punto de partida en la evolución jurídica de la ciudad. Está comúnmente aceptado que no todas las ciudades hispanas que en la obra de Plinio figuran como estipendiarias lo eran en el momento en que éste finalizó su obra. Más bien estamos hoy en condiciones de afirmar que algunas, con seguridad, habían cambiado ya de status jurídico, ascendiendo al rango de municipios. Aunque la fecha en que se produjo la promulgación del Edicto de Latinidad de Vespasiano es un asunto sobre el que existen diversas opiniones, parece ser que éste se publicó unos pocos años antes de que Plinio diera por finalizada su obra, a pesar de lo cual el autor no actualizó los datos (GARCÍA y BELLIDO, 1977, 79 y 101), por lo que no se recoge la más importante obra de municipalización en Hispania, las medidas tomadas por el emperador Vespasiano.

Por sí sola, esta noticia aportada por la mencionada fuente, no supone nada definitivo, excepto la prueba de que la promoción jurídica del municipio complutense no debió producirse antes de la época flavia. Si a esto añadimos los testimonios de individuos pertenecientes a la tribu Quirina, la época parece concretarse más en el período de gobierno de esta dinastía. Por fin, el apoyo arqueológico es definitivo. Con todos estos datos se puede intentar realizar una reconstrucción del proceso que, durante la segunda mitad del siglo I d. C., se pudo desarrollar en Complutum.

El castro ubicado en el cerro de San Juan del Viso sufrió, como toda la región, la presencia de los ejércitos romanos. La ausencia de datos en las fuentes y la falta de fortificación (pues la defensa natural del cerro por su lado sur es insuficiente), sugieren la posibilidad expuesta más arriba de que Complutum adoptara una posición neutral en la época de la conquista, y que prefiriera abrir sus puertas a los romanos antes que enfrentarse a ellos, pues su situación en un importante punto de paso la habría convertido en un objetivo inmediato de las tropas romanas, a fin de asegurarse el libre tránsito por el valle del Henares. Con la ocupación romana, se establecen allí una serie de individuos, probablemente llegados de otros lugares de la geografía peninsular, que vendrían atraídos por las posibilidades de este núcleo, ya pacificado, y que supondría un primer elemento romanizador de lo que, hasta entonces, no habría pasado de ser un núcleo indígena.
Desde el momento en que la vía que pasaba por la ciudad (8) comenzara a ser más frecuentada, hecho que debió ocurrir en la primera mitad del siglo I d. C., una pequeña parte de la población instalada en el cerro de San Juan del Viso descendería a la llanura, a fin de atender los servicios mínimos que el tránsito de personas y animales requería. Con el tiempo, el núcleo instalado en el valle debió crecer a mayor ritmo que la ciudad alta, hasta que, en determinado momento, el cerro quedó definitivamente abandonado.

El motor que debió impulsar este abandono es el cambio de status de esta ciudad peregrina, que, durante la dinastía flavia, se convertiría en municipio. Pero, dado que en el valle se había ido formando un núcleo a costa de la pérdida de habitantes del emplazamiento antiguo, y que el nuevo núcleo gozaba de una situación privilegiada con respecto al cerro, en especial por su función en el paso de la vía, hay que suponer que la concesión del nuevo status se otorgaría al núcleo del valle.

Allí, en la margen derecha del río Henares, se comenzó a llevar a cabo un proceso de transformación de la ciudad que, si bien ya podría contar con una infraestructura mínima, debía ser preparada para cumplir honrosamente con su rango municipal. La ya mencionada evidencia epigráfica sobre la Asamblea Decurional presupone la existencia de un edificio para su sede. Pero, al mismo tiempo, esto va unido a la existencia de otros magistrados: duumviros y aediles, y los consiguientes edificios que estarían al cuidado de estos últimos (D'ORS, 1953, 144). También se debieron levantar los lugares destinados al culto, como recuerdan las inscripciones de individuos dedicados al culto imperial, magistri, flamines y sevires (CIL II 3033 y 3034). Es muy probable que entonces se realizara un nuevo trazado de la ciudad, utilizando la vía como punto de referencia, como indica el que las inscrip-

(8) La fecha de su construcción no puede determinarse con precisión, aunque se admite comúnmente el reinado de Vespasiano como fecha probable, y posteriormente, en tiempos de Trajano y Decio, se realizaron las principales obras de mejora, como prueban los miliarios. Son tres los miliarios hallados en zonas próximas a Alcalá de Henares en relación con esta vía. Al año $101 \mathrm{~d}$. C., pertenecen $C I L$ II 4912 de Arganda y $C I L I I$ 4914 de las cercanías de Meco. Un tercer testimonio aducido es CIL II 4913, del que no se conoce el texto y que hoy se encuentra desaparecido. Sobre las circunstancias exactas de estos hallazgos y su descripción, ABASCAL PALAZÓN y FERNÁNDEZ-GALIANO, 1984, 26-27, n. ${ }^{\circ} 29$ a 31. 
ciones aparezcan en lo que parecen ser los límites del perímetro urbano.

El flamante municipio necesitaría una serie de edificios públicos de los que hasta entonces habría podido prescindir. Inmediatamente, las grandes familias ocuparían las magistraturas locales que se acababan de crear, para hacer posible el gobierno de la ciudad.

Por fin, hay que añadir que hubiera sido muy interesante la prueba de la existencia de más individuos complutenses pertenecientes a la tribu Quirina entre los abundantes testimonios epigráficos que ha aportado la ciudad, pero no hay que olvidar que la mención de esta tribu, aunque sólo aparezca en una inscripción, implica a tres individuos. Además, el texto corresponde a un epígrafe honorífico, lo que justifica el hecho de que no se omitiera ningún dato relativo al individuo a quien va dedicado. En cambio, en el resto de los epígrafes, no se consideraría necesario mencionar la tribu, porque sería la misma para todos estos individuos. Es más, debía ser probablemente la Quirina, según figura en la inscripción del flamen municipal porque, al no constar el origo de esta familia, hay que suponerla complutense.

En fin, todos los datos apuntan hacia un proceso de conversión en municipio, romano o latino, producido durante la dinastía flavia, apoyado por la adscripción del municipio a la tribu Quirina. Emperadores anteriores también pudieron utilizar esta tribu (KUBITSCHEK, 1882, 188-200), pero la cita de Plinio (III, 24) parece descartar una municipalización temprana que la presencia de la tribu Quirina situaría, en todo caso, bajo Claudio o Nerón, porque el cargo de Procurador de la Citerior ocupado por este autor durante el reinado de Vespasiano, y las noticias de su sobrino en torno a la continua actualización de la obra antes del año 77 d. C., aminoran la posibilidad de errores temporales de magnitud, como habría sido afirmar que Complutum era ciudad estipendiaria, si hiciera ya treinta años que había obtenido un nuevo status jurídico.

\section{EL FUNCIONAMIENTO ORGÁNICO DEL MUNICIPIO. LAS MAGISTRATURAS}

En primer lugar conocemos, como hemos mencionado, la existencia del Senado municipal, formado probablemente por un número elevado de decuriones, alrededor de 100, que lo integraban de forma vitalicia. Estos hombres constituían el ordo decurionum, es decir, el grupo social de rango más elevado dentro de la vida municipal, poseedores de una fortuna mínima de 100.000 sestercios.

Junto a esta Asamblea, habría unos duumviros (¿o IIIIviri?), los más altos magistrados del municipio. Desgraciadamente, no conocemos a ningún individuo que desempeñara tal cargo en Complutum, aunque no es necesario para saber de su existencia, ya que es consustancial a la vida municipal. Es de suponer que, en los primeros momentos de la municipalización, las magistraturas fueran monopolizadas por individuos pertenecientes a familias adineradas que se hubieran instalado en la ciudad. Este fenómeno se produjo en muchas ciudades en los momentos inmediatamente posteriores al cambio de status jurídico, dado que serían el elemento más romanizado y, en muchos casos, los que contaran con la fortuna necesaria para poder hacer frente a una magistratura. Posteriormente, la promoción social de otros individuos crearía una competencia para la ocupación de los cargos públicos que, en un primer momento, pudo no existir.

No se conoce tampoco a ningún individuo que desempeñara, en Complutum, la cuestura, es decir, aquel cargo por el que se administraba el tesoro municipal. En todo caso, de existir, tendrían que ser individuos con una cierta fortuna personal, ya que estaban obligados, al igual que los duumviros, a prestar el juramento de pecuniam comunem salvam foret, respondiendo con una parte de su fortuna como garantía para poder manejar los fondos públicos.

Al contrario de lo que ocurre con la cuestura, podemos asegurar la presencia de ediles, porque éstos existen en todos los municipios. Este cargo suponía, en muchos casos, el primer escalón en el cursus honorum municipal, desde el que podía pasarse a más altas magistraturas. No estaban sujetos al juramento para no malversar la hacienda pública, ya que no tenían acceso a ella. Se encargaban, fundamentalmente, del cuidado de los lugares públicos, mercados e imposición de multas, aunque no del cobro de las mismas.

Duumviros, ediles y cuestores (en el caso de que estos últimos existieran), tenían derecho a asistir a las reuniones de la Curia, aunque no podían emitir su voto. Así pues, en las decisiones tomadas por el Senado (Decreto Decurionum), como la que conocemos por la inscripción de Cn. Nonius Crescens y su familia, no estaba representada directamente la 
decisión de los magistrados. Eran los decuriones quienes elegían a los flamines, como ocurre con el mencionado individuo y, con frecuencia, éstos habían desempeñado antes magistraturas municipales (ETIENNE, 1974r, 236), pero no parece ser éste el caso del único flamen que conocemos en la ciudad, pues no queda constancia de ello en su épígrafe.

Si bien los hallazgos epigráficos en Complutum no han permitido el conocimiento de magistrados, en cambio, puede servir para ello una inscripción de la capital tarraconense. Se trata de un epígrafe honorífico, grabado en un pedestal, en honor de un flamen de la provincia llamado $L$. Caecilius Caecilianus (CIL II 4199. RIT 262), sobre el que G. Alföldy piensa que podría ser complutense por la similitud entre su nombre y el de otro individuo muerto en Complutum (Caecilius Caecilianus) (9). El flamen provincial fue, según consta en su propio epígrafe, duumviro por tres veces, y de ser cierto este orígen, tendríamos aquí al primer magistrado complutense conocido. La inscripción está fechada por Alföldy (RIT 262) entre los años 70 y $150 \mathrm{~d}$. C., mientras que el individuo complutense de igual nombre debió morir a finales del siglo I d. C., a juzgar por su inscripción, por lo que también cabe la posibilidad de que sean cercanos en el tiempo.

Se da la circunstancia de que $L$. Caecilianus Caecilianus pertenece a la tribu Quirina ya documentada en Complutum en la inscripción antes citada. Si se acepta para Complutum la municipalización de época flavia, ésta sería la tribu a la que se habría adscrito la ciudad, y a la que, asimismo, pertenecería L. Caecilius Caecilianus, honrado en Tarraco.

En fin, hay que suponer, a falta de otros datos, que el municipio complutense, tras el cambio de status jurídico, pasaría por una etapa de importante actividad constructiva para levantar los edificios que su nueva condición requería, y por una intensa vida ciudadana, que se prolongaría y enriquecería. durante el siglo II d. C., coincidiendo con el auge de la vida municipal, e impulsado por el papel cada vez más importante que la vía le proporcionara. A todo este proceso tuvo que ir unido un incremento

(9) D(is) M(anibus) / Caecil(ius) (Caecili/anus $\mathrm{Fa}^{5} / \mathrm{ni}$ Cae/cil (i) Polyc/hron(i) lib(ertus) [et] / At[t]iola f(ilia). CIL II 3039. ABASCAL Y FERNÁNDEZ-GALIANO, 1984, n. 24. progresivo de la población, que convertiría Complutum en un mosaico étnico en el que convivirían los habitantes originarios del lugar con familias venidas de otros puntos peninsulares.

\section{EL ÁREA DE INFLUENCIA DE LA CIUDAD}

Los hallazgos romanos de las inmediaciones de Alcalá de Henares sugieren para esta época un intenso poblamiento en la zona, en torno a la ciudad, por todos sus frentes. Especialmente numerosos son los hallazgos arqueológicos y epigráficos producidos a lo largo del valle del Henares, en dirección suroeste. Los actuales términos municipales de Torrejón de Ardoz, San Fernando de Henares y Barajas tuvieron en su territorio poblamiento romano de algún tipo, quizá en forma de villae.

Partiendo de Alcalá de Henares en otras direcciones también se encuentran restos romanos; así ocurre con poblaciones como Torres de la Alameda, Ribas-Vaciamadrid, Arganda; o en otras direcciones, Tielmes, Carabaña, Meco, etc.

Debieron ser numerosas las explotaciones agrícolas, villae, que con el tiempo se fueran estableciendo allí, ya que los campos circundantes eran propicios para su aprovechamiento, y algunas de estas villae ya han sido detectadas (10).

Por el suroeste, la intensidad del poblamiento se extiende hasta la actual ciudad de Madrid y sus alrededores (Carabanchel, Villaverde, Getafe, Casa de Campo), casi siempre en zonas cercanas a algún curso de agua. En algunos de estos lugares, los hallazgos han sido lo suficientemente abundantes como para sospechar de la existencia de una villa, pero en ocasiones se trata de restos cerámicos que no permiten asegurar el tipo de poblamiento que allí hubo; de hecho, éste sólo puede probarse en Villaverde, y suponerse en San Fernando de Henares y otros parajes cercanos a Alcalá. En conjunto, lugares de habitación romanos los hay en número considerable en todo el noroeste de lo que en otro tiempo había sido la región carpetana, con una cabeza administrativa que es el municipio de Complutum. Sin embargo, hay que mencionar el hecho de que algunos de estos puntos citados diste más de

(10) FUIDIO, 1934, cita la villa de Villaverde Bajo, excavada por Pérez de Barradas. FERNÁNDEZ-GALIANO, 1976, además de las que nombra en la propia Alcalá de Henares, también San Fernando de Henares, en los parajes de «Vega del Rincón» (p. 59), «Carretera de Mejorada» (p. 51), y «Km. 12 de Ajalvir a Loeches» (p. 53). 
un día de camino, en las condiciones de viaje de la época, del núcleo principal, lo que tampoco es un impedimento para su desarrollo y subsistencia, ya que las villae eran autosuficientes. Hay que suponer que estos núcleos aislados proliferarían notablemente en el Bajo Imperio, cuando la vida municipal entró en decadencia.

\section{EL ELEMENTO DEMOGRÁFICO}

Los hallazgos epigráficos complutenses son, comparados con los de otros núcleos de la Meseta, abundantes y variados en cuanto a la diversidad de datos que proporcionan. El panorama permite el conocimiento relativamente amplio de una parte de sus habitantes, suficiente para realizar un estudio onomástico y un esquema de su composición social, así como de los movimientos de población, bastante frecuentes, de los que ha quedado constancia. La documentación corresponde especialmente a los tres primeros siglos del Imperio, con una mayor incidencia en el I y II d. C., aunque no en todos los casos ha sido posible la datación.

Sólo una inscripción de las halladas en $\mathrm{Com}$ plutum hace mención de la tribu; se trata de una familia que deja constancia de su pertenencia a la tribu Quirina. En cambio, son frecuentes las menciones del origo extramunicipal, lo que da una idea, no sólo del importante número de población alóctona que allí viviría, sino de la diversidad de sus lugares de procedencia.

Asimismo, son muchos los casos en que se ha dejado constancia de la condición social de los individuos que figuran en las inscripciones, bien porque se haga mención expresa de ello, o bien porque los caracteres de la dedicación así lo hacen pensar.

Con todo esto se puede intentar reconstruir el panorama social de la Complutum romana.

Desde el momento mismo de la municipalización, o quizá con anterioridad, a Complutum debieron llegar familias de otros puntos que, en los casos en que poseyeran una fortuna considerable, se convertirian en la más alta burguesía local, y ocuparían las magistraturas al cambiar el status jurídico. La onomástica de las inscripciones refleja la existencia allí desde el siglo I d. C., es decir, desde fecha temprana, de familias con nomina y cognomina importantes dentro de la Península Ibérica. Estos grupos familiares se completan en ocasiones con los libertos, cuyos nombres, en muchos casos, demuestran quién ha sido su antiguo patrono. Los
Caecilii, Aemilii, Valerii, Iulii, Cornelii, Licinii y Nonii están presentes y suficientemente documentados en Complutum desde los primeros momentos del Imperio. En algunos casos, se trata de individuos con nombres plenamente romanos, y otros son personas con nomen romano y cognomen indigena o griego.

Cuando se otorga a la ciudad el estatuto de municipalidad, las familias acomodadas que allí se habían instalado se encuentran en una posición inmejorable para ocupar primeramente las magistraturas e integrar el ordo decurionum. Estos gentilicios arraigados se fueron extendiendo por la ciudad y sus alrededores, al ser adoptados por indígenas romanizados que, en muchos casos, son libertos que toman el nombre de su patrono a modo de reconocimiento.

Si la epigrafía ha permitido conocer algunas de las familias que, en los primeros siglos del Imperio, formaron la burguesía municipal complutense, también nos sirve para documentar la composición social de parte de la población, como son los libertos y esclavos de la ciudad. El número de epígrafes al respecto es bastante numeroso en comparación con el número total de individuos conocidos; en especial, los libertos forman un nutrido grupo en relación con las más importantes familias, a las que han servido antes como esclavos; su fidelidad y reconocimiento ante los antiguos patronos permite ahora conocer, no sólo su condición social, sino la posición que alcanzaron algunos de estos individuos, lo que les permitió incluso tener sus propios sirvientes.

Menos numeroso es el grupo de los esclavos conocidos, que se reducen a cuatro (dos de ellos, Olimpias y Menas, en la misma inscripción y con la misma đueña, Claudia Quieta, que a su vez es la dedicante) (ABASCAL y FERNÁNDEZ-GALIANO, 1984, n. 14), propiedad de grandes familias (Aemilii, Cornelii) (CIL II 3029) según consta en sus inscripciones.

Relacionado con los Aemilii está un esclavo llamado Calvus (ABASCAL y FERNÁNDEZ-GALIANO, 1984, n. ${ }^{\circ} 21$ ), a quien dedica una inscripción una mujer llamada Aemilia Arbuscula, probablemente una liberta de los Aemilii, la misma familia a la que pertenecía el difunto, aunque no lo hiciera constar en el epígrafe. La fórmula final (F.C.D.S.P.) es una muestra de la intención por parte de los libertos de dejar constancia de sus gas- 
tos, ya sea en favor de otra persona o del municipio. Es una afirmación de la posición económica alcanzada, que en ocasiones sería muy superior a su situación real en la escala social. Son frecuentes los libertos que quieren dejar constancia del gasto en que incurren (MANGAS, 1971, 251) al financiar una inscripción o algo aún más costoso. En Complutum los gastos de los libertos que conocemos se limitan al pago de las inscripciones.

Aunque hay testimonios de libertos del siglo I d. C., la mayor parte de los testimonios complutenses corresponden al siglo II. Esto nos proporciona una secuencia cronológica que abarca desde prácticamente los primeros momentos de la promoción jurídica de Complutum, intensificándose en el siglo II, coincidiendo con el auge de la vida municipal, que debió producir en la ciudad un aumento de población y una sensación de riqueza y bienestar como ocurrió en otros núcleos urbanos. El elevado número de libertos puede dar una idea sobre las familias poderosas de la ciudad, que debieron ser un elemento fuerte y no precisamente escaso, incluso antes de que Complutum cambiara su status de ciudad peregrina por el de municipio.

En cuanto a la promoción social de los libertos, la inscripción dedicada al Panteón de Augusto (11) informa sobre uno de ellos, que llegó a ser Sevir Augustal, L. Iulius Secundus. Su tria nomina indica que llegó a obtener la ciudadanía, pero además, tuvo que estar en posesión de una fortuna personal para poder hacer frente a los imperativos de su cargo. Son frecuentes los casos conocidos de sevires que dedican juegos circenses o algún otro tipo de espectáculo para sus conciudadanos. En general, los libertos que han adquirido, tras su manumisión, una determinada posición económica, dan frecuentes muestras de interés por evidenciarlo, concebido esto como medio de lograr una posición social que les separe de su antigua condición servil. Estos alardes de riqueza se traducen en actos diversos, desde la simple dedicación en un epígrafe, en el que hacen mención del desembolso efectuado, hasta ofrecimientos de juegos, de los que también dejan constancia en la epigrafía (PIERNAVIEJA, 1977, passim). Asimismo, conocemos en Complutum el caso de Aemilia Arbuscula (que debía ser li-

(11) Panthe(on) / Aug(usti) / sacrum / L(ucius) Iulius

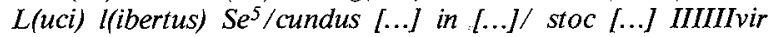
Aug(ustal) / D(e) s(ua) p(ecunia) f(aciendum) c(uravit) idemque $^{10} /$ dedicavit. CIL II 3030. berta), quien dedica, de su pecunio personal, una inscripción funeraria a un esclavo (vid. supra).

Por lo que se refiere al elemento griego, a pesar de la dificultad para fechar algunos epígrafes, podemos deducir dos hechos: la abundancia de individuos de nombre griego en Complutum, y su mayor intensidad en el siglo II d. C., coincidiendo con la prosperidad municipal, a pesar de que no siempre tras un nombre griego hay un individuo con ese origen.

Esta proliferación se justifica por la posición de la ciudad en un importante nudo viario, y los esclavos y libertos de nombre griego se vincularían, como sabemos para otros lugares (ESPINOSA RUIZ y PÉREZ RODRÍGUEZ, 1982), a funciones comerciales y artesanales, creciendo su número a medida que lo hacía la prosperidad de la ciudad. Muchos de ellos serían libertos que, al abandonar su condición servil, se ocuparían en funciones mercantiles, por lo que las posibilidades económicas del grupo debían ser muy heterogéneas. Complutum debió convertirse muy pronto en lugar de atracción para gente de muy variada condición, pero especialmente para aquellos que, por sus actividades, pudieran sacar más provecho de la ciudad. Lógicamente, estos nuevos pobladores se fueron asentando en el núcleo que nació junto a la vía romana, ya que era este lugar el que daría verdadera vida a la ciudad, antes incluso de convertirse en municipio.

El momento del cambio jurídico debió ser propicio para impulsar la llegada de gentes nuevas, que se unirían a las familias que hacía tiempo se habían asentado allí. Analizando estos movimientos de población, se puede apreciar una elevación en la intensidad de las migraciones, que no es ajena a los otros aspectos de la vida ciudadana.

Los individuos que especifican su origen no complutense en las inscripciones abarcan un período de algo más de un siglo. El testimonio más antiguo es del siglo I d. C.; se trata de Valerius Valerianus, segontino, muerto a los 22 años (ABASCAL y FERNÁNDEZ-GALIANO, 1984, n. ${ }^{\circ} 13$ ). De finales de este mismo siglo es Caecilius Ambi$n u s$, segoviense de 60 años (ABASCAL Y FERNÁNDEZ-GALIANO, 1984, n.$^{\circ}$ 3). En el siglo II d. C., hay varios casos de inmigrantes. Uno de ellos parece ser Fanius Caecilius Polychronius, que figura en el epígrafe funerario de su liberto Caecilius Caecilianus a finales del siglo I d. C., aunque tal vez figura en la inscripción sólo en calidad de 
patrono de un complutense, sin haberse desplazado nunca a esta ciudad.

Probablemente de esta misma época son también Licinius Iulianus y su madre Iulia, que llegaron a Complutum procedentes de Vxama, ciudad en la que están ampliamente documentados los $\mathrm{Li}$ cinii (12). A finales del siglo II d. C., G. Annius y Magia Atia, quizá un matrimonio, estaban también en Complutum, a donde habían llegado procedentes de Clunia (CIL II 5855).

Al mismo tiempo, hay dos testimonios de complutenses fuera de su ciudad, uno en la Península Ibérica y otro fuera de ella. El primero es C. Apuleius Lupus, complutense, que dedica una inscripción en Tarragona a su amigo L. Aemilius Sempronius Clemens Silvanianus en el siglo II d. C. (RIT 922). El otro es un individuo cuyo nombre no conocemos, pero que debió ser un complutense muerto en Roma, [Vr]be Italia d[ef]uncto (ABASCAL y FERNÁNDEZ-GALIANO, 1984, n. ${ }^{\circ} 18$ ), por lo que su esposa, Sulpicia Quinta, se encargó de dedicarle una lápida funeraria en Complutum, probablemente por ser ésta su ciudad de origen (la inscripción se fecha entre finales del siglo II y principios del III d. C.)

Durante el siglo II d. C. se desarrolló un fenómeno que, en mayor o menor medida, afectó a la vida de los municipios hispanos. Se produjo un impulso de la vida municipal a todos los niveles, favorecido especialmente por las capas más altas de la sociedad de esas ciudades, quienes contribuyen a proporcionar a sus núcleos urbanos la apariencia de grandeza y bienestar que ellos deseaban (D'ORS, 1953, 142). Esto debió ir acompañado de un desarrollo urbano, y, en muchos casos, de un aumento de población, con la aportación de individuos que buscaran participar en esa aparente opulencia. En la Complutum de esa época, el fenómeno debió producirse también, hasta el punto de que la mayor parte de los documentos epigráficos que nos han llegado corresponden a esa centuria. Entre finales del siglo I y finales del II d. C., vivieron la mayor parte de los individuos que conocemos, casi todos los libertos de las grandes familias e incluso ellas mismas; probablemente también es de esa época el único flamen municipal del que tenemos noticia, con su familia (Cn. Nonius Crescens, testi-

(12) CIL II 3036, Vxsa(mensis). Otros casos de Licinii de $V x a m a$, en JIMENO, 1980, n. ${ }^{\circ} 22$ y 80 ; en general en la provincia de Soria, n. ${ }^{\circ} 102,153$ y 170. monio único de la tribu Quirina), así como la mayoria de los individuos con nombre griego. Finalmente, también los testimonios de movimientos de población se producen, en su mayor parte, en esa época, pero mientras son varios los que conocemos de entrada y asentamiento en la ciudad, sólo dos individuos dejan constancia de su origen complutense fuera de su patria. Dentro de las limitaciones a las que un número tan reducido de casos obliga y del consiguiente margen de error, una cosa sí podemos afirmar: la migración complutense, al menos en los dos primeros siglos del Imperio, y especialmente en el II, debió dar como resultado un saldo positivo para la ciudad. Siete individuos (seis seguros y uno probable) contra dos, parecen en principio suficientes para suponer que, durante el siglo II d. C., la ciudad debió conocer una prosperidad que la convirtiera en un centro suficientemente atractivo para aumentar su población, con unos inmigrantes que parecen venir, mayoritariamente, de las ciudades de la Meseta norte.

\section{EL CULTO IMPERIAL}

Al contrario de lo que ocurre al intentar documentar las magistraturas municipalès, hay tres testimonios de lo que debió ser el culto imperial que se organizó en la ciudad.

Sabemos que Cn. Nonius Crescens ocupó dos cargos sacerdotales: magister y flamen de Roma y Augusto (Mag. flamin. Romae et Aug.), en una fecha que probablemente corresponde al siglo II d. C. (CIL II 3033), aunque no parece que pueda datarse con más exactitud. Esta inscripción fue dedicada por un hijo a su padre, con lo que conocemos las tres generaciones, ya que en el epígrafe no se ha omitido ni la filiación ni la tribu.

El flaminado municipal era un cargo al que se llegaba por elección del ordo decurional (ETIENNE, 1974r, 236), como ocurre en el caso que nos ocupa, en cuya inscripción figura la abreviatura D.D. (Decreto Decurionum), que hace referencia a la decisión de los decuriones con respecto al nombramiento para el flaminado. En cambio, no hay ninguna mención con respecto a un posible cursus honorum municipal de este individuo, que sería lo habitual antes de llegar a flamen. No es probable que, de haber ocupado algún cargo público con anterioridad, se hubiera omitido en una inscripción que se erige en su honor, y en la que se deja constancia de todos sus datos personales: tria nomina, 
tribu, filiación. Habría que pensar que este personaje ocupó en el municipio una posición social bastante elevada, hasta el punto de que la Asamblea de los Decuriones le erigiera en flamen municipal. No hay que olvidar que, ya de por sí, el flaminado debía ser ocupado por individuos económicamente poderosos. La ciudad, al nombrarlos, pasaba directamente a beneficiarse de las concesiones hechas por el personaje elegido. Los testimonios epigráficos dejan constancia de las liberalidades llevadas a cabo por los flamines y magistrados, fundamentalmente con motivo de su nombramiento. Es cierto que, corrientemente, los individuos que llegaban a desempeñar el flaminado municipal, habían sido antes magistrados (el orden lógico era edil, duumviro, flamen), lo que demuestra que poseían como mínimo la fortuna de 100.000 sestercios necesaria para acceder al ordo decurionum, pero tampoco faltan los casos de flamines para los que el desempeño de este cargo sería el escalón desde el que saltaran a las magistraturas municipales (13).

Cn. Nonius Crescens es flamen de Roma y Augusto, es decir, encargado de organizar este culto en la ciudad. El culto de Roma, como testimonio de culto imperial municipal (ETIENNE, 1974r, 293) llega a Complutum en un testimonio que parece del siglo II d. C.

El segundo testimonio es la inscripción de $L$. Iulius Secundus, que testifica la existencia, además de la institución del flaminado, de un colegio de sevires augustales en la ciudad; ambas funciones son producto del desarrollo urbano y municipal del núcleo, y debían desarrollar aspectos complementarios, relativos siempre al culto de los emperadores, ya que aparecen ambos coexistiendo. L. Iulius Secundus es el testimonio de la existencia del sevirato en Complutum, aunque no podemos concretar el momento exacto al que corresponde; J. Mangas $(1971,345)$ lo ha centrado, con reservas, en el siglo II, lo que corresponde al momento de auge del municipio complutense, pero lo más probable es que el culto imperial a través de los colegios de sevires sea un fenómeno que discurra de forma paralela a la municipalización.

En este caso concurren en el epígrafe varias circunstancias que hay que mencionar. En primer lugar, el dedicante, L. Iulius Secundus, tiene un

(13) BELTRÁN LLORIS, 1980, 394 ss., sobre un caso de individuo que tras el cargo sacerdotal (magister salorium) ocupa magistraturas municipales. nombre plenamente romano, probablemente, tomado de su patrono, de quien sabemos el praenomen, L(ucius), y suponemos razonablemente que el nomen era Iulius. El liberto tuvo una clara intención de dejar constancia de su condición como tal y de su origen servil, manteniendo aún una fuerte vinculación con su patrono, al que incluso menciona en el epígrafe. Su condición de sevir augustal le sitúa entre los individuos de mayor rango social dentro del grupo de los antiguos siervos. Se observa, en muchos casos, un interés por parte de los libertos, y muy especialmente de algunos que alcanzan el sevirato, por dejar constancia de su generosidad (PONS SALA, 1977, 215 ss.). Dentro de esta imagen dada por los libertos, y en especial por los sevires, encaja también la expresión de la fórmula final de esta inscripción: $d(e)$ s(ua) p(ecunia) f(aciendum) c(uravit), idemque dedicavit; es decir, el liberto paga de su propio bolsillo la inscripción, y la dedica al Panteón de Augusto. Otra dedicación igual (Pantheo Aug. sacrum) aparece en una inscripción hallada en Sevilla, dedicada también por un sevir augustal (CIL II 1165). En cualquier caso, el que $L$. Iulius Secundus deje constancia del nombre de su patrono indica el reconocimiento que le debía, quizá porque le hubiera ayudado a alcanzar la posición social que ostentaba.

La epigrafía ha sido, en muchos casos, un instrumento en el que los libertos han dejado reflejados los intereses que les mueven dentro de la sociedad de su época. El ascenso de un liberto dentro de la escala social es relativamente limitado, al menos es más limitado que sus posibilidades económicas, de manera que algunos de ellos llegaron a poseer importantes fortunas. La pertenencia a un colegio de sevires, con todo lo que eso lleva consigo en cuanto a ofrecimientos crematísticos a la ciudad, requiere una fortuna acumulada que, en la mayoría de los casos, es utilizada por el antiguo esclavo para reafirmar su papel dentro de la sociedad municipal. Son frecuentes las inscripciones ofrecidas por sevires, bien con carácter votivo, como ésta de Complutum, bien en conmemoración de espectáculos ofrecidos a la ciudad. En ambos casos se intenta dejar constancia de que la fortuna personal le permite esos gastos.

La inscripción de L. Iulius Secundus es, al mismo tiempo, un testimonio de la existencia del culto imperial organizado mediante un colegio de sevires, y también una manifestación espontánea de 
uno de ellos al objeto que justifica la existencia de su rango: los emperadores divinizados.

El último testimonio del culto imperial en Complutum, último también desde el punto de vista cronológico, es la inscripción dedicada a los Númenes del Emperador. Son escasos en la Península Ibérica los testimonios del culto imperial a través de los Númenes o genio de los difuntos imperiales (CIL II 3032). Se trata de una pieza de cuya existencia se ha dudado durante mucho tiempo, ya que se desconocía su paradero, pero que ha sido redescubierta (14) y hoy ya es un documento seguro. Es una inscripción tardía, de los siglos IV-V d. C., según Hübner, y que, por tanto, queda fuera de los límites cronológicos impuestos para este trabajo, pero es un testimonio de la continuidad, en época bajoimperial, del culto a los emperadores en el municipio, que ya conocemos sobradamente para el Alto Imperio, aunque, desgraciadamente, sin una fecha concreta para su introducción en la ciudad.

En resumen, conocemos en el municipio complutense la existencia de un culto imperial oficial, organizado sobre la base institucional de los magistri y flamines que, en determinado momento y tras la organización del culto al emperador, introduce también el de Roma. Paralelamente se organiza un colegio de sevires augustales, que es el instrumento por el cual, algunos individuos que proceden de una condición servil, convertidos en libertos, pueden participar en el culto a los emperadores, al tiempo que consiguen su propia promoción social.

Finalmente, hay un ejemplo de dedicación a una divinidad augustal, Marte Augusto, ofrecida por Apuleius Polydeuces (CIL II 3605), individuo de nombre griego. El sentido de Mars Augustus es, según Etienne (1974r, 341), el del emperador victorioso. La inscripción no ha sido fechada, y constituye el único testimonio de divinidad augustal hallado en Alcalá de Henares.

\section{LOS CULTOS ROMANOS}

En la epigrafía complutense no hay un solo testimonio de culto a una divinidad indígena. Los habitantes de Complutum dedican inscripciones a Marte, a Tutela, a las Ninfas, etc. Se trata de dioses romanos, pero, algunos de ellos, como ocurre con las Ninfas, suelen ser el testimonio de la asimi-

(14) Según ha podido comprobar recientemente el doctor Robert Knapp. lación de dioses indígenas con estas divinidades romanas menores, especialmente acompañadas de epítetos que constituyen el resto de este fenómeno de interpretatio (VÁZQUEZ Y HOYS, 1977, 11). Asimismo, el conjunto de las inscripciones responde a unos dedicantes que confirman una heterogénea composición social y un origen muy variado.

El dios romano más frecuente en Alcalá de Henares parece ser Marte. En Alcalá se han hallado tres inscripciones con esta dedicación, aunque una es de procedencia dudosa, ya que se ha querido situar su hallazgo en Salamanca, sin que la cuestión esté resuelta. De las tres inscripciones, una está dedicada a Mars Augustus (15), que se ha interpretado como la asimilación de un dios guerrero con el emperador. Las otras dos (CIL II 3027 y 3028), en cambio, están dedicadas a Mars, y no hay ningún indicio de que se trate de un proceso de interpretatio, aunque los nombres de los dedicantes son indígena y griego respectivamente, y en otras ocasiones en la Península Ibérica es frecuente la asimilación de Marte a un dios indígena. Estas dos inscripciones pueden ser contemporáneas o cercanas en el tiempo, ambas del siglo II d. C., fecha muy significativa en Complutum y a la que corresponden casi todas las dedicaciones a Marte. Estas manifestaciones a Marte no son un hecho aislado en Carpetania, ya que en un lugar tan alejado como es Collado Villalba se han encontrado dos inscripciones dedicadas a Marte, una de ellas con el apelativo Magnus. Es muy probable que en ambos casos, fechados respectivamente en época de Augusto y siglo II, se trate de una asimilación de este dios romano con un dios indígena, puesto que los nombres de los dedicantes así lo hacen suponer. Los individuos son Amia, de la gentilidad de los Aelariq(um) y Cantaber Elguismiq(um) (CIL II 3061 y 3062 ; ALBERTOS, $1975, \mathrm{n} .{ }^{\circ} 170$ y 171). La onomástica de estos dos individuos, así como su vinculación a las dos gentilidades, son suficientes pruebas de indigenismo para no ver en las inscripciones la manifestación del culto a un dios romano, sino un fenómeno de interpretatio con la divinidad indígena. De hecho, la manifestación del culto a Marte se produce en la Península en las zonas menos romanizadas (VÁZQUEZ Y HOYS, 1977,41 ss.)

(15) ABASCAL y FERNÁNDEZ-GALIANO, 1984, número 39, dedicada por Apuleius Polydences, que Fuidio (1934, 78 ) leyó Publio Vetelio Polydences, desoyendo la lectura correcta que había dado Hübner (CIL II 3605). 
La dedicación a Hércules está hecha por dos clunienses a mediados del siglo I d. C. (CIL II 5855. P. Anius y Magia Atia), y es el único testimonio de esta divinidad en Complutum y sus alrededores. El carácter aislado de la misma, y el origen foráneo de los dedicantes, nos hacen suponer que no debió ser una divinidad arraigada en la ciudad.

Diferente carácter revisten las dedicaciones a las Ninfas. El culto a las divinidades menores, como las Ninfas y los Lares, es muy bien acogido desde el principio por los indígenas, que encuentran mayor facilidad en asociarlas a sus dioses, y las aceptan mejor que a las divinidades de la religión oficial. En Alcalá de Henares hay un siervo, Attalus, perteneciente a la familia de los Cornelii, que dedica una inscripción a las Ninfas a principios del Imperio. Este caso, como las otras dedicaciones a las Ninfas, son probablemente la continuación de un culto indígena, asociado muy pronto al romano (VÁZQUEZ Y HOYS, 1977, 9).

Muy cerca de Complutum, en Arganda, hay otro testimonio de un ofrecimiento a las ninfas, en este caso a las Ninfas Varcilenae, cuyo dedicante es L. I. Rufinus (16). El nombre del dedicante es totalmente romano, excesivamente quizá para ofrecer una inscripción a este tipo de divinidades tan asociadas a las indígenas, especialmente cuando su nombre va, como en este caso, acompañado de un epíteto (Varcilenae). Debe tratarse de un indígena romanizado, quizá un liberto, que oculte, bajo este nombre, su origen y condición social.

Esta condición de liberto es segura, en cambio, en el caso de Flaccilla (CIL II 3031), que deja constancia de ello en el epígrafe dedicado a Tutela. Esta inscripción, que no ha podido ser fechada, nos da el único testimonio del culto a esta divinidad en toda la zona de influencia complutense. En este caso, la dedicante se aparta de la norma general, ya que los devotos de este dios son más corrientemente varones, pero es frecuente dentro de este grupo de los libertos al que pertenece Flaccilla, que piden protección o dan gracias por haberla obtenido (VÁZQUEZ Y HOYS, 1984, 556).

Fortuna está atestiguada en dos ocasiones, en epígrafes hoy perdidos y cuyos dedicantes no nos han llegado, por lo que sólo podemos suponer su

(16) CIL II 3067, en Arganda. Las Ninfas Varcilenae están entre las divinidades con las que se ha llevado a cabo la interpretatio; LAMBRINO, 1965, 223. aceptación en la zona, sin conocer ninguna cronología ni la extracción social de sus devotos, aunque parece ser frecuente este culto entre los libertos (VÁZQUEZ Y HOYS, 1984, 544).

A pocos kilómetros de Alcalá, en el término municipal de Meco, se hallaron dos epígrafes votivos, que hay que añadir al conjunto de Alcalá. Se trata, el primero de ellos, de una dedicación a Diana (Deanae sacrum), por cuya existencia, Fuidio supuso que allí debía haber un templo consagrado a esta diosa (FUIDIO, 1934, 78). La segunda es una inscripción cuya noticia ha llegado a través de Ambrosio de Morales, quien transcribió: Deabus / $M$. Grumius, pero Hübner supuso que la segunda línea puede ser una corrupción de sacrum (CIL II $3024)$.

Finalmente, hay que mencionar la inscripción votiva hallada en Barajas y dedicada a $I$ (ovi) $O(p t i$ mo) M(aximo) (CIL II 3063). El nombre del dedicante no puede leerse claramente por fractura de la pieza, y la lectura de Hübner es Coeli Melis..., que Higuera leyó Caelia Meliasa. En cualquier caso, se trata del único testimonio de este culto en todos los alrededores de Alcalá de Henares, y ha sido fechado en el siglo II d. C. Las dedicaciones a Júpiter son abundantísimas en toda la Península Ibérica. Vázquez y Hoys las calcula en $186(1977,19)$, de las que 111 corresponden a la Tarraconense. Parece que estaba extendido su culto especialmente entre los libertos, sobre todo en zonas muy romanizadas (la de Barajas está en una zona muy poblada en época romana, como es el valle del Henares), y con una mayor intensidad en los siglos II y III .

El conjunto de las dedicaciones de Alcalá de Henares y su zona cercana nos aporta los nombres de varias divinidades romanas, siete concretamente, $\mathrm{y}$ en cambio, ningún testimonio de dioses indígenas. A pesar de estos datos, de los que parece deducirse un alto grado de romanización, hay algunos casos en los que se aprecia un proceso de sincretismo, de asimilación de dioses romanos a los indígenas, en dedicaciones hechas por los hispanos, que han conservado su nombre o que se hallan bajo un nombre latino.

\section{FACTORES DE DESARROLLO DE LA CIUDAD}

En el cerro de San Juan del Viso existía ya, tal como hemos mencionado, un asentamiento prerromano del tipo de los castros que se extienden por la 
Meseta sur, en los momentos anteriores a la presencia romana. Durante el siglo II a. C., con la pacificación de la zona, se inició el asentamiento de elementos romanos y, en general, de individuos procedentes de zonas más romanizadas, que pronto comenzaron a incrementar el pequeño núcleo formado al borde de la vía y que cumplía las funciones de mansión.

Cuando se produce el cambio de status jurídico, convirtiéndose Complutum en municipio, ya debía tener ese núcleo del valle una cierta consistencia, lo suficiente como para que se formara allí el nuevo municipio.

Su situación, junto a una de las principales arterias del interior peninsular, que unía dos capitales provinciales (Emerita y Tarraco) (ROLDÁN, 1975, 232), debió constituir el principal motor de desarrollo urbano y económico. Es fácil que, lo que había comenzado siendo una mansión, se convirtiera poco a poco en un importante centro de comercio, que atraería a una gran masa de población de otras ciudades, principalmente comerciantes que vieran las posibilidades que el lugar les ofrecía. Así se explica la existencia del elemento griego, en número importante, que como se ha visto para otras ciudades (ESPINOSA RUIZ y PÉREZ RODRÍGUEZ, 1982) debe desarrollar una actividad comercial dentro del sector económico básico de la ciudad.

El desarrollo de Complutum atrajo también a un buen número de familias, ya fuertemente romanizadas, que llegan de otros lugares de la Península, principalmente de la Meseta norte, instalándose allí y convirtiéndose algunos de ellos en oligarquía municipal, al tiempo que en fuerte elemento romanizador, siendo su presencia muy temprana.

El fenómeno de la municipalización debió servir para dar una categoría administrativa a la ciudad que respondiera a su situación real, un núcleo cuya importancia en la Meseta iba creciendo progresivamente, y quizá con un cierto desarrollo urbanístico, que la municipalización ayudó a impulsar.

El siglo II d. C. es el de la culminación.de este proceso, como indican todos los datos que la ciudad aporta, tanto arqueológicos como epigráficos, coincidiendo con el florecimiento municipal en el resto de la Península (D'ORS, 1953, 142). En esta centuria tenemos testimonios de las grandes familias complutenses; de un elevado número de libertos que constituyen, como en otros lugares, el ele- mento social más dinámico (PONS SALA, 1977) por su interés de promoción social, pero que además hubieron de jugar un importante papel en el desarrollo económico de la ciudad, y en algunos casos, acumularon una considerable fortuna.

De esta segunda centuria son, en definitiva, las muestras de bienestar y prosperidad del municipio, fruto de la actividad mercantil que constituía su función principal, y que debía estar acompañada de un cierto alarde de riqueza en las construcciones.

El comercio debió favorecer desde muy pronto los contactos de los habitantes de Complutum con individuos de diversos lugares y condiciones sociales, que constituirían una población flotante considerable. Incluso las grandes familias del municipio estarían vinculadas a esta actividad económica, además de sus libertos, algunos de los cuales debieron reunir un cierto capital en función de sus relaciones comerciales. Por Complutum pasarían los productos que fueran llevados por tierra a todos los puntos de la Meseta sur, así como a Lusitania meridional y parte de la Bética. Asimismo, sería lugar de paso de otros productos que, desde todos esos lugares, salieran por los Pirineos. En cuanto al aprovisionamiento de alimentos para la ciudad, no debió ser difícil, ya que es una zona bastante fértil y cuenta con cursos de agua, lo que explicaría la dispersión del poblamiento romano en la comarca, del que nos dan cuenta los restos encontrados a lo largo del valle del Henares y en los alrededores de Alcalá en todas las direcciones (vid. supra).

La crisis municipal del siglo III d. C. debió afectar también a esta ciudad, que deja de proporcionarnos abundantes restos epigráficos desde esa centuria, al menos con la intensidad de los dos primeros siglos del Imperio, pero el poblamiento se mantuvo durante el Bajo Imperio, con una importancia que queda atestiguada por las más recientes excavaciones en el valle (FERNÁNDEZ-GALIANO y MÉNDEZ MADRIAGA, 1984), a lo que hay que unir la tradición literaria que enlaza con la propagación del Cristianismo en Hispania.

\section{BIBLIOGRAFÍA}

ABASCAL PALAZÓN, J. M. y FERNÁNDEZ-GALIANO, D., 1984: «Epigrafia Complutense». Museos, 3, 7-36.

ALBERTOS FIRMAT, M. ${ }^{a}$ L., 1975: «Organizaciones suprafamiliares de la Hispania antigua», $B S A A$, XL-XLI, y Studia Archaeologica, 37. 
ALFÖLDY, G., 1975: Die römischen Inschriften von Tarraco. Berlín.

ALMAGRO GORBEA, M., 1976-78: «La iberización de las zonas orientales de la Meseta», Ampurias, 38-40, 93 ss.

BELTRÁN LLORIS, F., 1980: Epigrafía latina de Saguntum y su territorium. Trabajos Varios del SIP, n. ${ }^{\circ} 67$. Valencia.

CUADRADO, E., 1976-78: «Influencias de la iberización en el interior peninsular», Ampurias, 38-40, 325 ss.

D’ORS, A., 1953: Epigrafía jurídica de la España romana. Madrid.

ESPINOSA RUIZ, U., y PÉREZ RODRÍGUEZ, A., 1982: « $T r i$ tium Magallum. De ciudad peregrina a municipio romano"s, $A E A, 55, \mathrm{n} .^{\circ} 145-146,65$ ss.

ÉTIENNE, R., 1974r: Le culte imperial dans la Péninsule Ibérique d'Auguste a Dioclétien. París.

FERNÁNDEZ-GALIANO, D., 1976: Carta arqueológica de Alcalá de Henares y su partido. Alcalá de Henares.

FERNÁNDEZ-GALIANO, D., y MÉNDEZ MADARIA GA, A., 1984: «La ciudad romana de Complutum», Revista de Arqueología, n. ${ }^{\circ} 43,23$ ss.

FUIDIO RODRÍGUEZ, F., 1934: Carpetania romana. Madrid.

GAGÉ, J., 1971: Les classes sociales dans l'Empire romain. Paris.

GALSTERER, H., 1971: Untersuchungen zum römischen Städtewesen auf der Iberischen Halbinsel. Berlín.

- 1979: «Bemerkungen zur Integration vorrömischer Bevölkerungen auf der Iberischen Halbinsel», en Actas del II Coloquio sobre lenguas y culturas prerromanas de la Península Ibérica (Tübingen, 1976), 433 ss. Salamanca.

GARCÍA Y BELLIDO, A., 1977: La España del siglo I de nuestra Era. Madrid.

GIL FARRÉS, O., 1966: La moneda hispánica en la Edad Antigua. Madrid.

JIMENO, A., 1980: Epigrafia romana de la provincia de Soria. Soria.
KUBITSCHEK, W., 1882: De romanarum tribuum origine ac propagatione. Wien.

LAMBRINO, S., 1965: «Les cultes indigénes en Espagne sous Trajan et Hadrien», en Les Empereures romains $d^{\prime} E s$ pagne, 223-242. París.

McELDERRY, R. K., 1918: "Vespasian's reconstruction of Spain», JRS, VIII, 53 ss.

- 1919: "Vespasian's reconstruction of Spain. Addenda», $J R S, \mathrm{IX}, 86$ ss.

MANGAS MANJARRÉS, J., 1971: Esclavos y libertos en la España romana. Salamanca.

MONTENEGRO, A., 1975: «Problemas y nuevas perspectivas en el estudio de la España de Vespasiano», $H A$, $\mathrm{V}, 7$ ss.

PIERNAVIEJA, P., 1977: Corpus de inscripciones deportivas de la España romana. Madrid.

PONS SALA, J., 1977: «Algunas consideraciones teóricas sobre el sevirato como indicador de dinamismo socioeconómico», Memorias de Historia Antigua, I, 215 ss. Oviedo.

ROLDÁN HERVÁS, J. M., 1975: Itineraria Hispana. Valladolid.

SANCHO ROCHER, L., 1981: El convento jurídico caesaraugustano. Zaragoza.

UNTERMANN, J., 1976: «Leyendas monetales», en I Coloquio sobre lenguas y culturas prerromanas de la Península Ibérica, 213 ss. Salamanca.

VALIENTE CÁNOVAS, S., y BALMASEDA MUNCHAR A Z ,

L., 1983: «Hacia una delimitación de la Carpetania en la Edad de Hierro II», Homenaje al Prof. Martín Almagro Basch, I, 135 ss. Madrid.

VÁZQUEZ Y HOYS, A. M. ${ }^{a}$., 1977: «La religión romana en Hispania I. Análisis estadístico», $H A$, VII, 7 ss.

- 1984: La religión romana en Hispania. Fuentes epigráficas, arqueológicas y numismáticas. Madrid.

VIVES Y ESCUDERO, A., 1926: La moneda hispánica. Barcelona. 